NASA/TM-2004-213390

\title{
Results of an Advanced Development Zero Boil-Off Cryogenic Propellant Storage Test
}

David Plachta

Glenn Research Center, Cleveland, Ohio 
Since its founding, NASA has been dedicated to the advancement of aeronautics and space science. The NASA Scientific and Technical Information (STI) Program Office plays a key part in helping NASA maintain this important role.

The NASA STI Program Office is operated by Langley Research Center, the Lead Center for NASA's scientific and technical information. The NASA STI Program Office provides access to the NASA STI Database, the largest collection of aeronautical and space science STI in the world. The Program Office is also NASA's institutional mechanism for disseminating the results of its research and development activities. These results are published by NASA in the NASA STI Report Series, which includes the following report types:

- TECHNICAL PUBLICATION. Reports of completed research or a major significant phase of research that present the results of NASA programs and include extensive data or theoretical analysis. Includes compilations of significant scientific and technical data and information deemed to be of continuing reference value. NASA's counterpart of peerreviewed formal professional papers but has less stringent limitations on manuscript length and extent of graphic presentations.

- TECHNICAL MEMORANDUM. Scientific and technical findings that are preliminary or of specialized interest, e.g., quick release reports, working papers, and bibliographies that contain minimal annotation. Does not contain extensive analysis.

- CONTRACTOR REPORT. Scientific and technical findings by NASA-sponsored contractors and grantees.
- CONFERENCE PUBLICATION. Collected papers from scientific and technical conferences, symposia, seminars, or other meetings sponsored or cosponsored by NASA.

- SPECIAL PUBLICATION. Scientific, technical, or historical information from NASA programs, projects, and missions, often concerned with subjects having substantial public interest.

- TECHNICAL TRANSLATION. Englishlanguage translations of foreign scientific and technical material pertinent to NASA's mission.

Specialized services that complement the STI Program Office's diverse offerings include creating custom thesauri, building customized databases, organizing and publishing research results ... even providing videos.

For more information about the NASA STI Program Office, see the following:

- Access the NASA STI Program Home Page at http://www.sti.nasa.gov

- E-mail your question via the Internet to help@sti.nasa.gov

- Fax your question to the NASA Access Help Desk at 301-621-0134

- Telephone the NASA Access Help Desk at 301-621-0390

- Write to:

NASA Access Help Desk

NASA Center for AeroSpace Information 7121 Standard Drive

Hanover, MD 21076 
NASA/TM-2004-213390

\section{Results of an Advanced Development Zero Boil-Off Cryogenic Propellant Storage Test}

David Plachta

Glenn Research Center, Cleveland, Ohio

Prepared for the

40th Joint Propulsion Conference and Exhibit

cosponsored by AIAA, ASME, SAE, and ASEE

Fort Lauderdale, Florida, July 11-14, 2004

National Aeronautics and

Space Administration

Glenn Research Center 
Available from

NASA Center for Aerospace Information 7121 Standard Drive

Hanover, MD 21076
National Technical Information Service 5285 Port Royal Road Springfield, VA 22100

Available electronically at http://gltrs.grc.nasa.gov 


\title{
Results of an Advanced Development Zero Boil-Off Cryogenic Propellant Storage Test
}

\author{
David Plachta \\ National Aeronautics and Space Administration \\ Glenn Research Center \\ Cleveland, Ohio 44135
}

\section{Abstract}

A zero boil-off (ZBO) cryogenic propellant storage concept was recently tested in a thermally relevant low-earth orbit environment, an important development in the effort to apply this concept to flight projects. Previous efforts documented the benefits of ZBO for launch vehicle upper stages in a low-earth orbit (LEO). Central to that analysis is a ZBO Cryogenic Analysis Tool that estimates the performance of each component and the ZBO system. This test is essential to the validation of that tool, and was the first flight representative configuration tested in a thermally representative environment. The test article was comprised of a spherical $1.4 \mathrm{~m}$ diameter insulated propellant tank, with a submerged mixer, a cryogenic heat pipe, flight design cryocooler, and a radiator. All were enclosed in a thermal shroud and inserted into and tested in a vacuum chamber that simulated an LEO thermal environment. Thermal and pressure control tests were performed at sub-critical $\mathrm{LN}_{2}$ temperatures and approximately 2 atmospheres pressure. The cold side of the ZBO system performed well. In particular, the heat pipe performed better than expected, which suggests that the cryocooler could be located further from the tank than anticipated, i.e. on a spacecraft bus, while maintaining the desired efficiency. Also, the mixer added less heat than expected. The tank heating rate through the insulation was higher than expected; also the temperatures on the cryocooler hot side were higher than planned. This precluded the cryocooler from eliminating the boil-off. The results show the cryocooler was successful at removing $6.8 \mathrm{~W}$ of heat at approximately $75 \mathrm{~K}$ and $150 \mathrm{~W}$ of input power, with a heat rejection temperature of $311 \mathrm{~K}$. The data generated on the ZBO components is essential for the upgrade of the ZBO Cryogenic Analysis Tool to more accurately apply the concept to future missions.

\section{Introduction}

The purpose of ZBO is to control tank pressure without the need to vent propellant, using a synergistic application of active refrigeration (via a cryocooler) and multi-layer insulation. In this case, the heat enters the tank walls, primarily through radiation, and is removed by a submerged fin heat exchanger coupled to the cryocooler. The cryocooler rejects the heat to the cryoshroud (which simulates the LEO temperature) through a radiator.

Predecessors to this development test were two successful ZBO tests, ${ }^{1,2}$ both of which provided important stepwise developments of this concept. The test reported here is an important evolution of the concept because it is more representative of flight, mainly because of the use of a flight-like cryocooler.

This testing was a step in a roadmap to advance the ZBO concept toward future flight applications with cryogenic upper stages of launch vehicles. Recent analysis shows substantial benefit ${ }^{3}$ of $\mathrm{ZBO}$ when compared to passive cryogenic propellant storage for low earth orbit (LEO). Accordingly, this development test was performed in a simulated LEO environment, under vacuum and with an environmental temperature of $230 \mathrm{~K}$. Note that no tank shading nor any radiation model was created to determine the actual environment temperatures of the configuration.

Flight representative components were used, where possible, including a joint Air Force/NASA developmental high efficiency flight-type cryocooler along with a one-of-a-kind cryogenic heat pipe. The test hardware configuration used is shown in figure 1.

The principal development reported here is the integration of the flight cryocooler, including a flexible coupling, a cryogenic heat pipe, and a submerged mixer to a cryogenic storage tank. This provides important information to validate analytical models on the overall system efficiency, system control, forced convection requirements (coupling of the mixer to the heat exchanger), and the effects of heat rejection. ${ }^{3}$ 


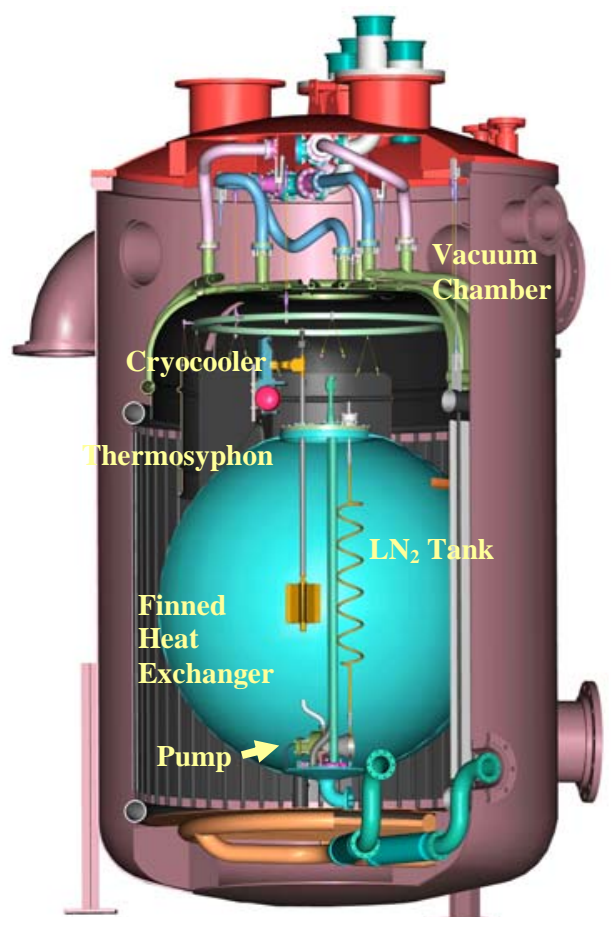

Figure 1.-Test Configuration. This cutaway model shows the arrangement of the key components within the propellant tank and the cryocooler.

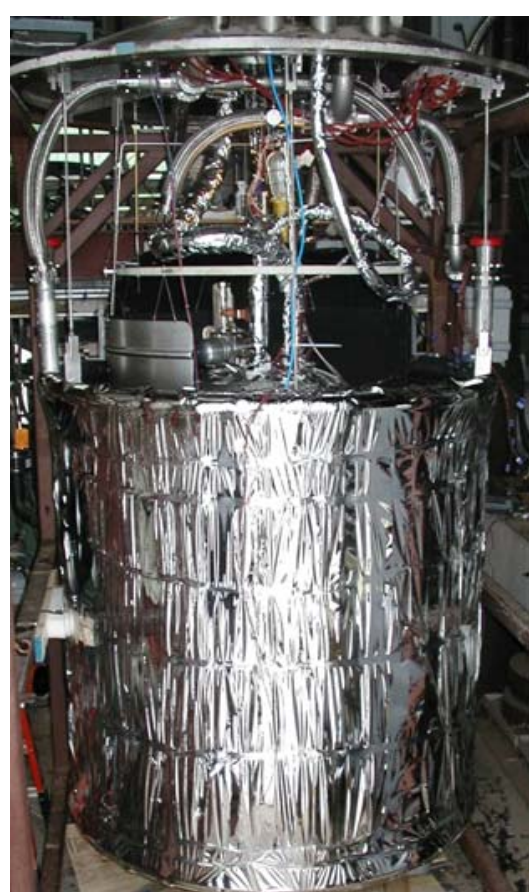

Figure 2.-Test Hardware. The full assembly is supported from the vacuum chamber lid. The cryocooler and radiator are visible above the cylindrical shroud. The top cryoshroud is not present in this photo.

\section{Experimentation}

\section{A. Facility}

NASA Glenn Research Center's Small Multi-Purpose Research Facility (SMiRF), is a test bed used to evaluate the performance of thermal management systems. The vacuum chamber, $1.8 \mathrm{~m}$ diameter by $3 \mathrm{~m}$ long, produces a vacuum of $1.8 \times 10^{-5}$ torr. The cylindrical cold $\mathrm{GN}_{2}$ shroud, used to provide a controlled thermal environment to the test article, was augmented with a top and bottom section of similar design to provide a completely enclosed thermal shroud. The shroud was controlled to $230 \mathrm{~K}$ ( 227 to $233 \mathrm{~K}$ ). In addition, the shroud sections are covered with a mylar sheet, to even-out their temperature and reduce the thermal load. Figure 2 shows this assembly, minus the top shroud, being lowered into the vacuum chamber.

\section{B. Test Article}

Tank: The tank is spherical with a diameter of $1.4 \mathrm{~m}$. It is a thin-walled, flight-weight tank made of 2219 aluminum. The tank is hung from the vacuum chamber lid with six stainless steel cables, $0.6 \mathrm{~cm}$ thick. For tests, the tank is filled with LN2 at $138 \mathrm{kPa}(20 \mathrm{psia})$.

Insulation: The insulation on the test tank consists of two multi-layer insulation (MLI) blankets. Each blanket is comprised of 17 double aluminized mylar (DAM) radiation shields alternatively spaced with double silk net spacers. Two blankets are used, for a total of 34 layers of MLI. The blankets are held together with Nylon fasteners and reinforced Mylar cover sheets. Nylon button-pin studs, epoxied to the tank wall, support the blankets. Approximately $2 / 3^{\text {rds }}$ of the tank is covered with this insulation, which was originally fabricated and tested in 1977 was used again in $1998 .{ }^{1}$ The other third of the insulation was replaced using similar materials and construction. 
The outside layer of older insulation had evidence of oxidation and the blankets did not assemble to the tank as neatly as they had in 1998. However, it was not replaced.

Fitted MLI blankets, comprised of approximately 10 layers of mylar, are assembled to insulate the tank supply, vent, and drain lines as well as the cryocooler flexible link and cryogenic heat pipe. Velcro and aluminized mylar tape are used to attach this insulation. The insulated tank, as assembled to the vacuum tank lid, is shown in figure 3. The estimated tank heating rate with this insulation is $6.8 \mathrm{~W}$.

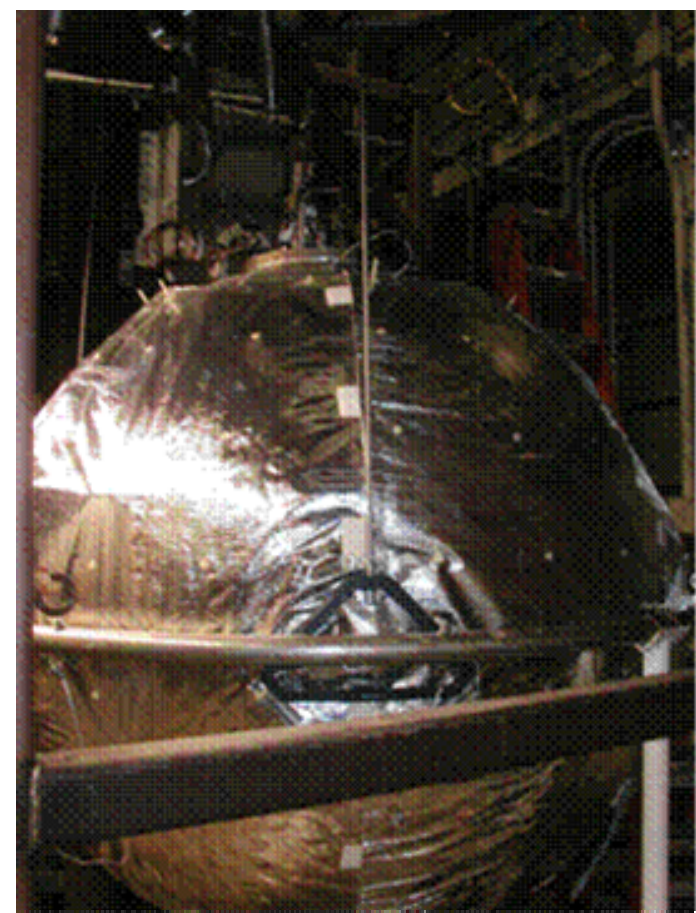

Figure 3.-14 $\mathrm{m}$ dia spherical tank shown with insulation assembled.

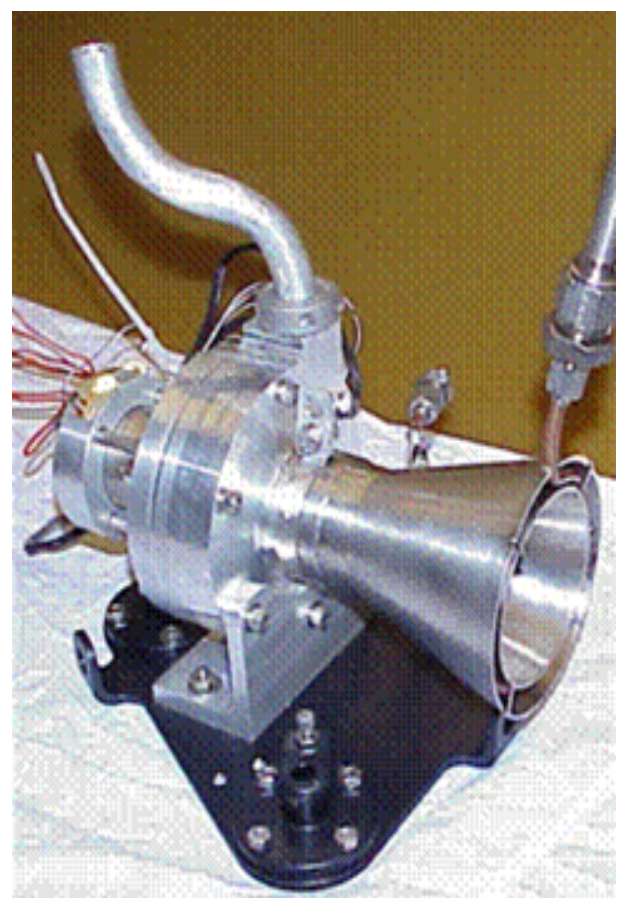

Figure 4.-Pump used to destratify LN2. Pump was mounted inside the tank, on the bottom baffle plate. Its outflow was directed to the fin on the thermosyphon.

Heat Removal System: A pump is mounted off the bottom baffle plate inside the test tank. With a design flow rate of 33 liters per minute and a differential head of $1.5 \mathrm{~m}$ at $10 \mathrm{~W}$ input power, this pump can easily break up the top stratified layer of the tank liquid when the tank is filled. The pump is shown in figure 4.

The pump outlet is directed at the fin of the heat echanger, which is located equidistant from the top and bottom of the tank. The pump moved the heat that entered the sidewalls and circulated it to the fin; natural convection also moved heat to the fin. The fin is soldered to the heat pipe, or "thermosyphon." The thermosyphon is an original design. It is sized so that the evaporator area is 3 times bigger than the condenser, which helps maintain a relatively constant thermal resistance over a broad range of temperatures. A design fill level of $15 \%$ was used to keep the maximum pressure in the pipe to a reasonable level. The thermosyphon is charged with high purity GN2 gas at 225 psi.

The selected design's calculated thermal resistance is $0.335 \mathrm{~K} / \mathrm{W}$, with a heat flow of $8 \mathrm{~W}$. It is interesting to note that a solid copper rod of the same dimensions would have a thermal resistance of $12.5 \mathrm{~K} / \mathrm{W}$ at $77 \mathrm{~K}$. The thermosyphon design and its performance is described in more detail in reference 4.

The fin end of the thermosyphon is the evaporator. In it, heat causes evaporation which then moves to the condenser. The condenser is mated through a flexible link to the cryocooler. The exterior of the thermosyphon is vacuum jacketed to prevent removal of heat that migrates to the top of the tank, to better represent a low-gravity application. The vacuum jacket on the thermosyphon is welded to a flange that is mated to the tank. The thermosyphon and fin are shown in figure 5. 


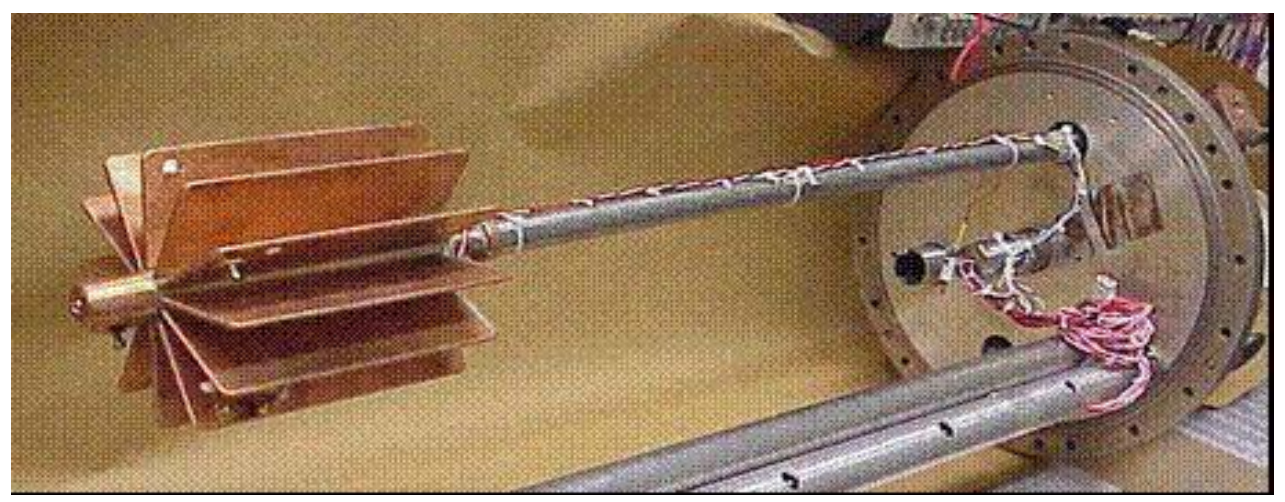

Figure 5.-Thermosyphon. Cryogenic heat pipe or "thermosyphon" shown assembled to tank lid. Copper fin is soldered to the evaporator.

The cryocooler is a High Efficiency Cryocooler (HEC), designed and fabricated by Northop Grumman under funding from NASA and the Air Force Research Laboratory. It was designed for an actual flight application, but has not yet been qualified for flight. It has a capacity of $10 \mathrm{~W}$ of heat removal at $95 \mathrm{~K}$ ( $300 \mathrm{~K}$ rejection temperature). Performance curves developed at the Air Force Research Laboratory indicate that it could remove $7 \mathrm{~W}$ of heat at an input power of $140 \mathrm{~W}$ under our expected conditions $(75 \mathrm{~K})$, which appears to be enough to achieve ZBO at LEO. The cooler weighs just $4 \mathrm{~kg}$. It is shown mounted on the radiator in figure 6.

Heat is rejected through the radiator, also depicted in figure 6. The radiator is a solid aluminum structure and serves to support the cryocooler while rejecting its heat along with that entering the test tank. The majority of heat is rejected to the cryoshroud, although a portion is intercepted by the tank itself. The radiator interior, which is where the cryocooler is mated is painted black. The exterior was left unpainted. The radiator is supported by stainless steel wires from a low-conductivity Micarta ring, which is hung via Kevlar cables from the vacuum chamber lid. The radiator did not come into contact with the cryogenic tank walls, although at its perimeter it is very close to the outside layer of tank insulation.

During assembly, pneumatically actuated pins hold the radiator/cryocooler assembly to the test tank lid to prevent substantial movement of this structure as it hangs from the vacuum chamber lid. Those pins are retracted prior to installation into vacuum chamber.

In an actual flight configuration, the cryocooler and radiator assembly would likely be mounted on the spacecraft bus and the propellant tank would be shielded from the hot radiator.

Test tank temperature sensors are used primarily for fill level information and liquid temperature. The instrumentation on the thermosyphon is used to determine its performance and the flexible link temperature data is used to find the heat going in the cryocooler. It was calibrated at temperature prior to the test. The pump speed is used to determine its outflow and its heat addition to the tank. Temperature data on the plumbing

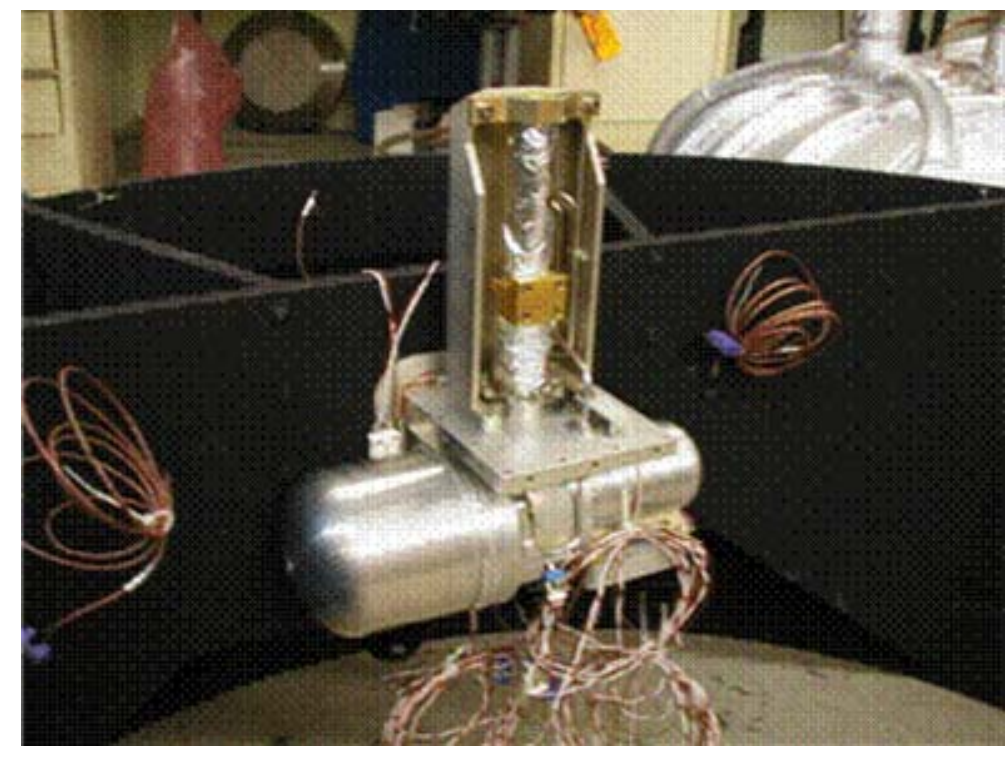

Figure 6.-Cryocooler HEC Cryocooler shown mounted on radiator. It was designed to remove $10 \mathrm{~W}$ at $95 \mathrm{~K}$. and support cables is used to determine the heat entering the tank from those sources. The temperature sensors on the outside of the insulation are used to determine if the insulation temperatures are steady.

Cryocooler power is only locally available at the power source, which includes two true power meters. These meters are also used to calibrate the pump power. Videotape is used to verify and time stamp these measurements.

Facility instrumentation includes an ion gauge for the vacuum level, a gas analyzer, and 30 thermocouples on the cryoshroud. 
Test Sequence: The vacuum chamber is pumped down for several days to remove as much vapor as possible. The insulation was purged with GN2. The cryoshroud system is brought down to the desired temperature. When the vacuum chamber gas analyzer indicates that the vapor is gone, the test tank was filled with LN2 to $99 \%$ full. During this process, the tank is vented to prevent overpressure. When the vent rate and the exterior insulation are steady over several hours, the cryocooler is turned on to eliminate boil-off. The tank mixer is turned on periodically to destratify and move the heat to the fin.

\section{Results}

The first test determined that the baseline heating rate was be $9.4 \mathrm{~W}$. This was significantly higher than expected. This same tank and insulation was tested in $1998^{2}$ with liquid hydrogen, where it was found to have a heating rate of $14.5 \mathrm{~W}$, which when adjusted for LN2 and the different environmental temperature used for these tests, is equivalent to $6.8 \mathrm{~W}$. That heating rate was less than that of the same insulation that was fabricated in the late 1970's (ref. 4). Obviously, substantial degradation of the insulation properties has occurred.

The tank strut heating was $0.7 \mathrm{~W}$. The heating rate from the cryocooler, when off, was $0.9 \mathrm{~W}$. The heat soak back from the radiator on the MLI was $0.2 \mathrm{~W}$.

\section{A. Cold Side Performance}

Table 1 charts the temperatures between the cryocooler and the liquid nitrogen in the tank. The temperature difference is a substantial system inefficiency, despite our efforts to minimize this delta $T$. The actual and design temperatures are both shown. The most significant difference between and design and actual temperatures is the difference in the fin and saddle temperatures. This is where the thermosyphon was located and it proved to have half the thermal resistance predicted based on other heat pipes. Note that few have been made of this size and temperature, and there is little design data. The condenser and evaporator sizes were well matched, which contributed to its outstanding performance. (see fig.7 and ref. 4).

This design is somewhat relevant to the micro-g environment, which would use a heat pipe with wicking. Wicking affects start-up and not the performance of condenser or evaporator. The thermosyphon's entrainment along the walls could aide response and might serve to reduce $\Delta \mathrm{T}$. That would not occur in a heat pipe with wicking. While the flow characteristics and heat pipe start-up would be different and potentially more difficult, this development means that heat pipe length should have minimal effect, within reason, permitting more flexibility in cryocooler configuration, potentially sharing heat loads, compressors, and controllers.

Table 1.-Temperatures of the cold side heat removal system of the ZBO test set-up.

\begin{tabular}{|l|l|l|}
\hline & Predicted K & $\begin{array}{c}\text { Actual } \\
\mathrm{K}\end{array}$ \\
\hline Liquid & 82.4 & 82.4 \\
\hline Fin (evaporator) & 82.1 & 82.3 \\
\hline Condensor & 79 & 81.3 \\
\hline Flex Link hot & 78.1 & 79.2 \\
\hline Flex link cold & 74 & 75.6 \\
\hline Cryocooler & 73.8 & 75.5 \\
\hline Total Drop & 8.6 & 6.9 \\
\hline
\end{tabular}

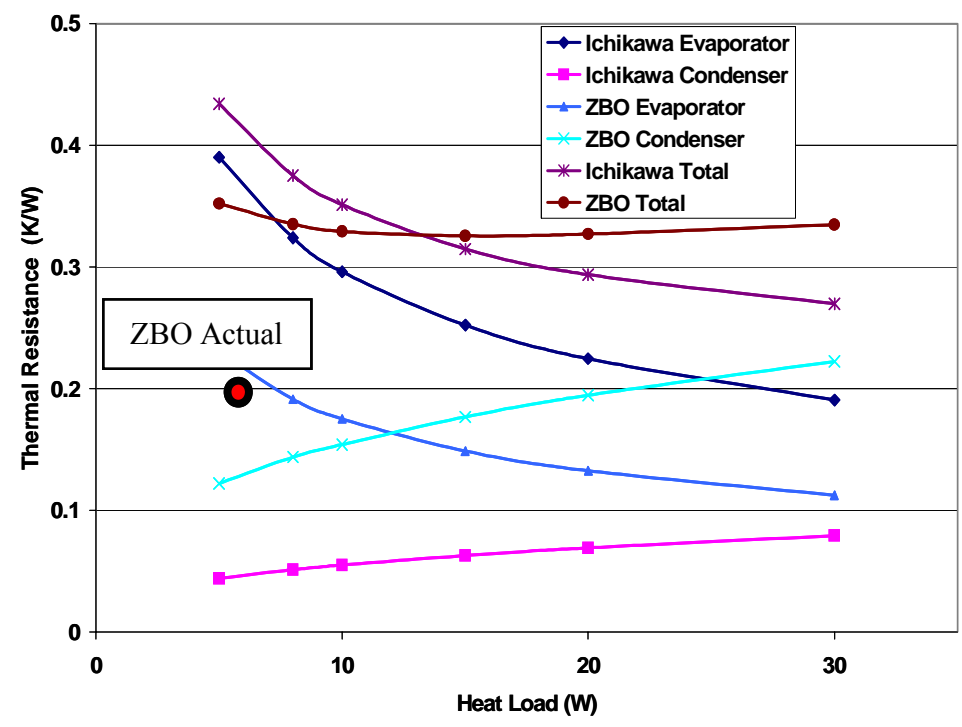

Figure 7.-The thermosyphon performed much better than expected. The close matching of the evaporator and condenser was responsible. 


\section{B. Mixer Performance}

The mixer was very effective in destratifying the propellant. It took only 30 seconds to do so, at a mixer power of $3.5 \mathrm{~W}$. With our pump duty cycle of once per 90 minutes, this equals $0.058 \mathrm{~W}$ of average power (which is heat that the cryocooler must remove). Furthermore, if the pump is sized for an in-space application, then it would only need to overcome cryogen surface tension forces, further reducing the pump power requirement to $0.0007 \mathrm{~W}$ for $\mathrm{LO} 2 ; 0.0014$ for $\mathrm{LH}_{2}{ }^{3}$

The mixer was not needed for heat removal. The heat removal rate did not increase when the pump was on. This was not anticipated. For these ground tests, free convection was sufficient to move the heat from the tank walls to the fin, which was in the center of the tank (see fig. 1). This is because of the low viscosity of the cryogen, which contributes to a high Grashoff number (a high Grashoff number results in high free convection rates). It is also proportional to gravity, so in the microgravity environment of space, free convection rates will be substantially reduced.

\section{Radiator Performance}

The heat from the test tank $(9.4 \mathrm{~W})$ and the heat from the cryocooler compressor $(150 \mathrm{~W})$ went to the radiator. The radiator's purpose was to minimize the cryocooler hot side temperature by moving this heat out to the cryoshroud. The temperatures on the radiator were $311 \mathrm{~K}$, which was $21 \mathrm{~K}$ warmer than anticipated. Because the cryocooler cold side temperature is dependent on this temperature, this caused the cryocooler cold-side to be warmer for the same input power, which is additional system inefficiency. Post-test radiator analysis explored many radiator concepts, to determine the potential improvement in its performance and the best design for an in-space application of this size. A different radiator that included a capillary heat pipe and additional struts would have reduced the cryocooler interface temperature to $273 \mathrm{~K}$, or $43 \mathrm{~K}$ above the shroud temperature. This would have improved the heat removal capacity to $7.8 \mathrm{~W}$, which still would not have been enough to achieve ZBO.

\section{Tank Pressure Control}

Tank pressure versus time is shown in figure 8 . While the cryocooler reduced the pressure rise rate, it was not sufficient to remove the heat that entered the tank. Steady state pressure control has not yet been achieved.

Figure 9 shows that pump speed and duration did not have an effect on the tank pressure control.

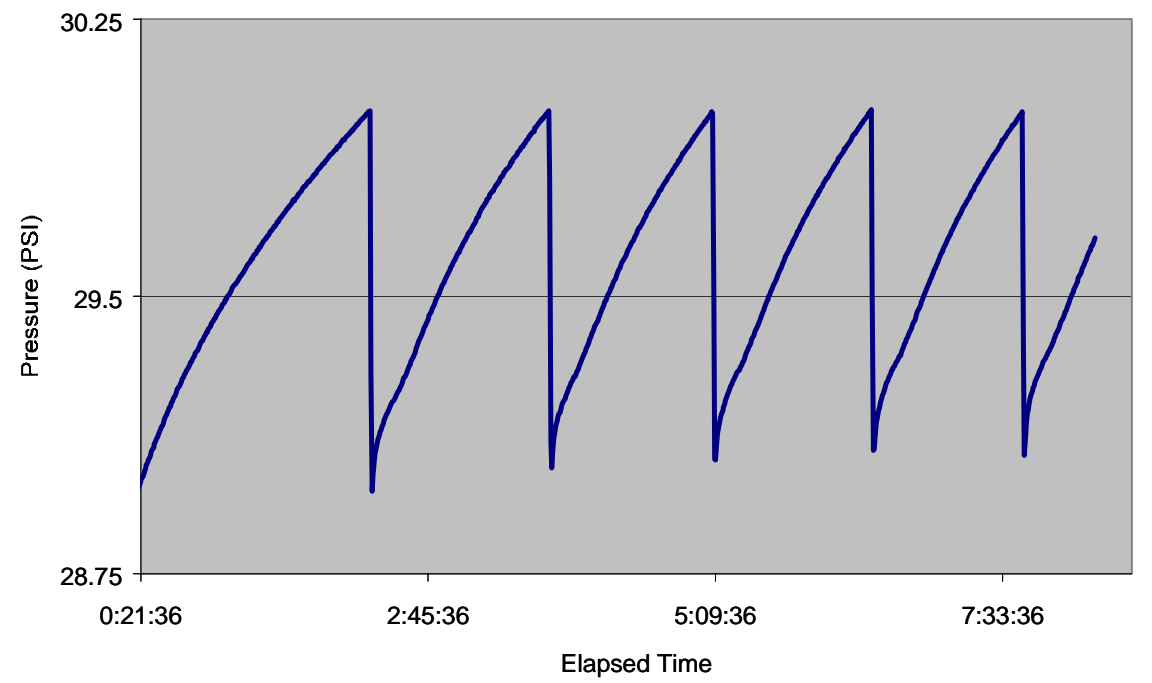

Figure 8.-Tank pressure data with tank filled with LN2. Q = 6.6 W, 98\% full tank, 227 $\mathrm{K}$ Cryoshroud. Pressure (psi) on the Y-axis. Steady state was never reached. 


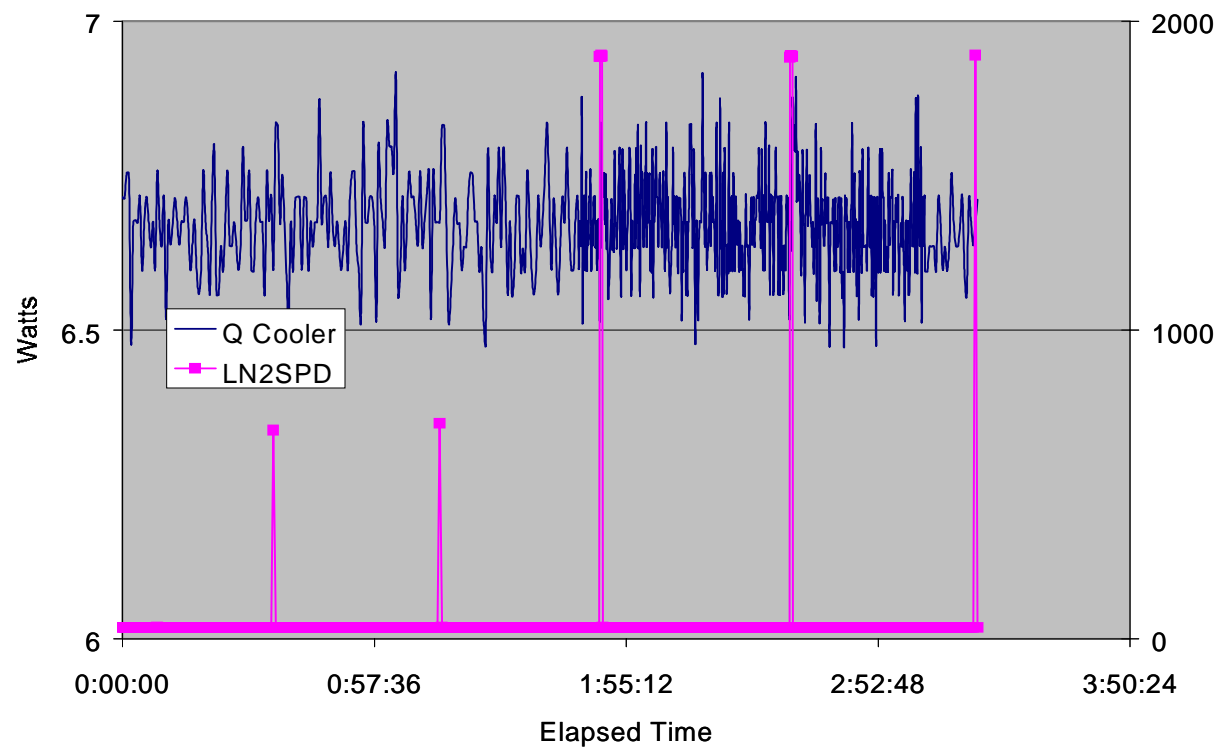

Figure 9.-Changes in pump speed or on time had no affect on heat removal rate.

\section{Future Work}

Analysis has begun on an actual spacecraft configuration with a cryogenic propulsion stage in a zero boil-off configuration. The spacecraft thermal model will determine if the low-Earth orbit temperature of $230 \mathrm{~K}$ used in this test is too conservative. Preliminary results indicate that sunshades and spacecraft bus shielding can dramatically reduce this temperature and substantially reduce the cooling requirements. This thermal model combined with the test data obtained here will be the basis for follow-on testing or future modeling.

\section{Conclusion}

The baseline tank heating rate was too high to achieve zero boil-off with the cryocooler and radiator used. The primary source of the problem was poor insulation, which had degraded through years of storage. From the data obtained on the cryogenic heat pipe, it appears that cryocoolers can be located on the spacecraft bus instead of close coupling with the propellant tank - a much-improved situation. This is due to the low temperature gradient of the thermosyphon and its relative insensitivity to length. Also, the average power required for the mixer was less than anticipated. The developments on the heat pipe, mixer, and the radiator will be incorporated in the ZBO Cryogenic Analysis Tool and adds important definition and data that will be applied to future ground tests and to in-space mission concepts.

\section{References}

${ }^{1}$ D. Plachta, "Hybrid Thermal Control Testing of a Cryogenic Propellant Tank," NASA Technical Memorandum 1999-209389, Adv. Cryo. Eng., Vol. 45 (Kluwer, New York, 2000) 465.

${ }^{2}$ A. Heyayat, L. Hastings, C. Bryant, D. Plachta, "Large Scale Demonstration of Liquid Hydrogen Storage With Zero-Boil-Off," Adv. in Cryo. Eng., 47, (AIP, New York, 2002), 1276.

${ }^{3}$ D. Plachta, P. Kittel, "An Updated Zero Boil-Off Cryogenic Propellant Storage Analysis Applied to Upper Stages or Depots in an LEO Environment, NASA/TM-2003-211691, presented at the 2002 AIAA Joint Propulsion Conference, Indianapolis, Indiana, July 8, 2002.

${ }^{4}$ R. Christie, D. Plachta, "Design and Operating Characteristics of a Cryogenic Nitrogen Thermosyphon," to be published, presented at the Cryogenic Engineering Conference, Anchorage, Alaska, September 23-25, 2003. 
Public reporting burden for this collection of information is estimated to average 1 hour per response, including the time for reviewing instructions, searching existing data sources, gathering and maintaining the data needed, and completing and reviewing the collection of information. Send comments regarding this burden estimate or any other aspect of this collection of information, including suggestions for reducing this burden, to Washington Headquarters Services, Directorate for Information Operations and Reports, 1215 Jefferson Davis Highway, Suite 1204, Arlington, VA 22202-4302, and to the Office of Management and Budget, Paperwork Reduction Project (0704-0188), Washington, DC 20503.

\begin{tabular}{|l|l|l}
\hline 1. AGENCY USE ONLY (Leave blank) & $\begin{array}{c}\text { 2. REPORT DATE } \\
\text { November } 2004\end{array}$ & $\begin{array}{r}\text { 3. REPORT TYPE AND DATES COVERED } \\
\text { Technical Memorandum }\end{array}$ \\
\hline
\end{tabular}

\section{TITLE AND SUBTITLE}

Results of an Advanced Development Zero

Boil-Off Cryogenic Propellant Storage Test

\section{AUTHOR(S)}

David Plachta

\section{FUNDING NUMBERS}

WBS-22-800-59-04

\section{PERFORMING ORGANIZATION NAME(S) AND ADDRESS(ES)}

National Aeronautics and Space Administration

John H. Glenn Research Center at Lewis Field

Cleveland, Ohio 44135-3191
8. PERFORMING ORGANIZATION REPORT NUMBER

E-14898

\section{SPONSORING/MONITORING AGENCY NAME(S) AND ADDRESS(ES)}

National Aeronautics and Space Administration

Washington, DC 20546-0001

10. SPONSORING/MONITORING AGENCY REPORT NUMBER

NASA TM-2004-213390

AIAA-2004-3837

\section{SUPPLEMENTARY NOTES}

Prepared for the 40th Joint Propulsion Conference and Exhibit cosponsored by AIAA, ASME, SAE, and ASEE, Fort Lauderdale, Florida, July 11-14, 2004. Responsible person, David Plachta, organization code 5870,

216-977-7126.

Unclassified - Unlimited

Subject Categories: 16, 20, and 28

Distribution: Nonstandard

Available electronically at http://gltrs.grc.nasa.gov

This publication is available from the NASA Center for AeroSpace Information, 301-621-0390.

\section{ABSTRACT (Maximum 200 words)}

A zero boil-off (ZBO) cryogenic propellant storage concept was recently tested in a thermally relevant low-earth orbit environment, an important development in the effort to apply this concept to flight projects. Previous efforts documented the benefits of ZBO for launch vehicle upper stages in a low-earth orbit (LEO). Central to that analysis is a ZBO Cryogenic Analysis Tool that estimates the performance of each component and the ZBO system. This test is essential to the validation of that tool, and was the first flight representative configuration tested in a thermally representative environment. The test article was comprised of a spherical $1.4 \mathrm{~m}$ diameter insulated propellant tank, with a submerged mixer, a cryogenic heat pipe, flight design cryocooler, and a radiator. All were enclosed in a thermal shroud and inserted into and tested in a vacuum chamber that simulated an LEO thermal environment. Thermal and pressure control tests were performed at sub-critical $\mathrm{LN}_{2}$ temperatures and approximately 2 atmospheres pressure. The cold side of the ZBO system performed well. In particular, the heat pipe performed better than expected, which suggests that the cryocooler could be located further from the tank than anticipated, i.e. on a spacecraft bus, while maintaining the desired efficiency. Also, the mixer added less heat than expected. The tank heating rate through the insulation was higher than expected; also the temperatures on the cryocooler hot side were higher than planned. This precluded the cryocooler from eliminating the boil-off. The results show the cryocooler was successful at removing $6.8 \mathrm{~W}$ of heat at approximately $75 \mathrm{~K}$ and $150 \mathrm{~W}$ of input power, with a heat rejection temperature of $311 \mathrm{~K}$. The data generated on the ZBO components is essential for the upgrade of the ZBO Cryogenic Analysis Tool to more accurately apply the concept to future missions.

14. SUBJECT TERMS

Cryocoolers; Cryogenics; ZBO; Zero boil-off; Propellant storage, Cryogenic thermal control

\begin{tabular}{|c|c|c|}
\hline $\begin{array}{c}\text { 17. SECURITY CLASSIFICATION } \\
\text { OF REPORT } \\
\text { Unclassified }\end{array}$ & $\begin{array}{c}\text { 18. SECURITY CLASSIFICATION } \\
\text { OF THIS PAGE } \\
\text { Unclassified }\end{array}$ & $\begin{array}{c}\text { 19. SECURITY CLASSIFICATION } \\
\text { OF ABSTRACT } \\
\text { Unclassified }\end{array}$ \\
\hline
\end{tabular}



